\title{
The adsorption and unfolding kinetics determines the folding state of proteins at the air-water interface and thereby the equation of state
}

\author{
Peter A. Wierenga ${ }^{\mathrm{a}, \mathrm{b}, *}$, Maarten R. Egmond ${ }^{\mathrm{c}}$, Alphons G.J. Voragen ${ }^{\mathrm{b}}$, Harmen H.J. de Jongh ${ }^{\mathrm{a}, \mathrm{d}}$ \\ ${ }^{a}$ Wageningen Centre for Food Sciences, P.O. Box 557, Diedenweg 20, 6700 AN, Wageningen, The Netherlands \\ ${ }^{\mathrm{b}}$ Wageningen University and Research Centre, Wageningen, The Netherlands \\ ${ }^{c}$ Utrecht University, Utrecht, The Netherlands \\ ${ }^{\mathrm{d}}$ TNO Quality of Life, Zeist, The Netherlands \\ Received 19 October 2005; accepted 8 March 2006
}

Available online 13 March 2006

\begin{abstract}
Unfolding of proteins has often been mentioned as an important factor during the adsorption process at air-water interfaces and in the increase of surface pressure at later stages of the adsorption process. This work focuses on the question whether the folding state of the adsorbed protein depends on the rate of adsorption to the interface, which can be controlled by bulk concentration. Therefore, the adsorption of proteins with varying structural stabilities at several protein concentrations was studied using ellipsometry and surface tensiometry. For $\beta$-lactoglobulin the adsorbed amount $(\Gamma)$ needed to reach a certain surface pressure $(\Pi)$ decreased with decreasing bulk concentration. Ovalbumin showed no such dependence. To verify whether this difference in behavior is caused by the difference in structural stability, similar experiments were performed with cytochrome $c$ and a destabilized variant of this protein. Both proteins showed identical $\Pi-\Gamma$, and no dependence on bulk concentration. From this work it was concluded that unfolding will only take place if the kinetics of adsorption is similar or slower than the kinetics of unfolding. The latter depends on the activation energy of unfolding (which is in the order of $100-300 \mathrm{~kJ} / \mathrm{mol}$ ), rather than the free energy of unfolding (typically $10-50 \mathrm{~kJ} / \mathrm{mol}$ ).
\end{abstract}

(c) 2006 Elsevier Inc. All rights reserved.

Keywords: Surface denaturation; Protein adsorption; Air-water interface; Surface equation of state

\section{Introduction}

To understand the differences in surface behavior observed between different proteins-or one protein in different system conditions-it is necessary to identify the different processes involved in adsorbed layer formation and their relative contribution to the interfacial properties. One of these processes is the possible unfolding of proteins at the interface [1-3]. That proteins may unfold at interfaces was hypothesized based on the observation that enzymes may loose their activity upon adsorption at the air-water interface [4,5]. A gain in free energy of the system would be obtained if the protein changes its conformation so that the polar residues are oriented towards the aqueous phase and the non-polar (or hydrophobic) residues to

\footnotetext{
* Corresponding author. Fax: +31 317484893 .

E-mail address: peter.wierenga@wur.nl (P.A. Wierenga).
}

the air phase. Such a reorientation will lead to a 'loop-train' configuration, where loops are the parts of the polypeptide that protrude in the bulk solution and the trains are segments of mainly hydrophobic residues that are adsorbed at the interface $[3,6,7]$. In what way the observed interfacial properties are affected by such unfolding is not well understood. Some authors suggest that only an unfolded protein will adsorb at the interface, thereby relating structural stability to the initial adsorption $[1,8,9]$. Other authors claim that protein unfolding is required to increase the surface pressure [10-12]. In these models the conformational state of the proteins is often assumed to change with the surface pressure. In the equation of state model of Fainerman et al. $[13,14]$, the decrease in apparent size of the adsorbed protein with increasing surface pressure is described as desorption of segments of the protein chain. However, from studies performed with non-unfolding particles (such as Stöber silica particles [15], glass microspheres [16], gelled polymer 
microbeads [17], latex particles [18], and colloidal silver particles [19]) surface pressure-surface area relations are found that are remarkably similar to those typical for proteins. Another observed phenomenon that has been related to protein unfolding after adsorption is the increase in surface pressure at longer time-scales, while little or no increase in adsorbed amount is measured $[2,7,20]$. The above-mentioned articles illustrate the different phenomena that have been related to interfacial unfolding of proteins.

In contrast to the relative high amount of theories based on protein unfolding at liquid interfaces, the direct evidence seems to be limited. Detailed information on the exact globular structure of adsorbed proteins can be obtained from only a few techniques. Most techniques that can readily be used in bulk are difficult to apply in a reflection mode due to drastic decreases in signal intensity and subsequently a decrease of the signal to noise ratio. Neutron and X-ray reflectivity have been used to obtain information on the density profile and structure of interfacial molecular layers [21-29], but the results cannot be decisive about possible conformational changes of proteins at the interface. More specific information on the structural fold of proteins at the air/water interface can be obtained from infrared reflection absorption spectroscopy (IRRAS). With this method, the spectrum of an infrared (IR) beam is analyzed after specular reflection at the interface. The sensitivity of the amide I region to changes in the secondary structure can be used to gain insight in the protein conformation at a secondary folding level [30-35]. More recently also external reflection circular dichroism has been used to assess this information [33]. From a combination of these techniques, several authors conclude that only limited changes in the conformation of proteins occurs upon adsorption at the air-water interface [28,32,34,36-40]. Maximum changes of up to $10 \%$ are observed in the secondary structure, but the globular folding state of the protein is generally found to remain intact [34]. Furthermore, no significant changes of the structure in time have been reported so far.

With respect to characterizing the surface functionality of proteins it is important to learn in what way protein unfolding at interfaces affects the measured interfacial properties such as surface pressure. Therefore the current work focused on changes in the adsorbed state of the protein as a result of adsorption at rates, rather than differences between the adsorbed state and the conformation in bulk. Since the rate of adsorption is directly proportional to the bulk concentration of the protein, the adsorption of proteins with different structural stabilities at different bulk concentrations was measured with the use of ellipsometry and surface tensiometry.

\section{Materials and methods}

$\beta$-Lactoglobulin ( $\beta$-lg) was isolated and purified ( $>98 \%$ purity) from fresh cow milk (A:B ratio 40:60) using the protocol described by de Jongh et al. [41]. The material was freeze-dried and stored at $-20^{\circ} \mathrm{C}$. Ovalbumin was isolated as described previously [42] with the only adaptation that ovalbumin was eluted from the ion-exchange material at $0.15 \mathrm{M} \mathrm{NaCl}$ to improve purity. Horse heart cytochrome $c$ was purchased from
Sigma-Aldrich (C7752), and dialysed against demineralised water, freeze-dried and stored at $-20^{\circ} \mathrm{C}$ until use.

\subsection{Destabilization of cytochrome $c$}

A destabilised form of cytochrome $c$ was produced by reductive alkylation of the methionine- 80 as described by de Jongh et al. [43]. In this method the methionine- 80 is first dissociated from the heme-group and then acetylated by incubating the protein $(4 \mathrm{mM})$ in the presence of $24 \mathrm{mM}$ iodacetic acid, $50 \mathrm{mM}$ sodium acetate $(\mathrm{pH} 1.5)$ and $0.5 \mathrm{M} \mathrm{NaCl}$ at $37^{\circ} \mathrm{C}$ for 8 h. Far-UV CD and absorbance measurements $(375-425 \mathrm{~nm}$ to measure the Soret band as an indication for the presence of the heme-group) confirmed that the modification was complete, and that the modified protein exhibited the same structure as the non-modified protein under ambient conditions (results not shown).

\subsection{Change in free energy by urea titration}

The structural stability of the proteins at $20^{\circ} \mathrm{C}$ was determined by monitoring the intrinsic fluorescence of tryptophan and tyrosine residues at increasing urea concentrations as described by Broersen et al. [44]. A 10-M urea stock solution was prepared by dissolving $1.103 \mathrm{~g}$ of urea (Sigma) per mL of phosphate buffer ( $\mathrm{pH}$ 7.0). The protein samples were prepared by diluting a $5-\mu \mathrm{L}$ of a $10-\mathrm{mg} / \mathrm{mL}$ solution in $1 \mathrm{~mL}$ urea-buffer mixture. Protein solutions $(0.1 \mathrm{mg} / \mathrm{mL}$ or $2.7 \mu \mathrm{M}$ in $10 \mathrm{mM}$ phosphate $\mathrm{pH} 7.0)$ at increasing concentrations urea $(0-8 \mathrm{M}$ at $0.2 \mathrm{M}$ intervals) were prepared one day before measurement, to ensure complete equilibration of the samples. Spectra were measured using a Cary Med Eclipse (Varian) fluorimeter, with excitation and emission slit widths of $5 \mathrm{~nm}$. The excitation wavelength was $295 \mathrm{~nm}$ and the emission spectra were recorded from 300-400 nm with a scan speed of $100 \mathrm{~nm} / \mathrm{min}$. Each spectrum was the average of two scans and corrected for a protein-free sample. The titration curves were plotted by taking the band intensity for a fixed emission wavelength $(310 \mathrm{~nm})$ as a function of denaturant concentration. The free energy of unfolding was calculated from an extrapolation of the free energy of unfolding at increasing urea concentrations-assuming two-state unfolding — as described elsewhere $[44,45]$.

\subsection{Adsorption behavior}

The adsorption of proteins to the air-water interface and subsequent development of surface pressure was measured using a Multiskop ellipsometer (Optrell, Germany) combined with a Langmuir trough (Riegler and Kirstein, Germany) and Wilhelmy plate tensiometry. If proteins adsorb to the interface the ellipsometric angles $\Delta$ and $\Psi$ are increased depending on the concentration in and the thickness of the adsorbed layer [46]. The values for the ellipsometric angles $\Delta$ and $\psi$ can be used to calculate the adsorbed amount. To do this, the refractive index and thickness of the adsorbed protein layer are fitted in a model that constitutes of two bulk phases (air and water) and one adsorbed layer, with parameters: $n_{\text {air }}=1.000, n_{\text {protein solution }}=$ 


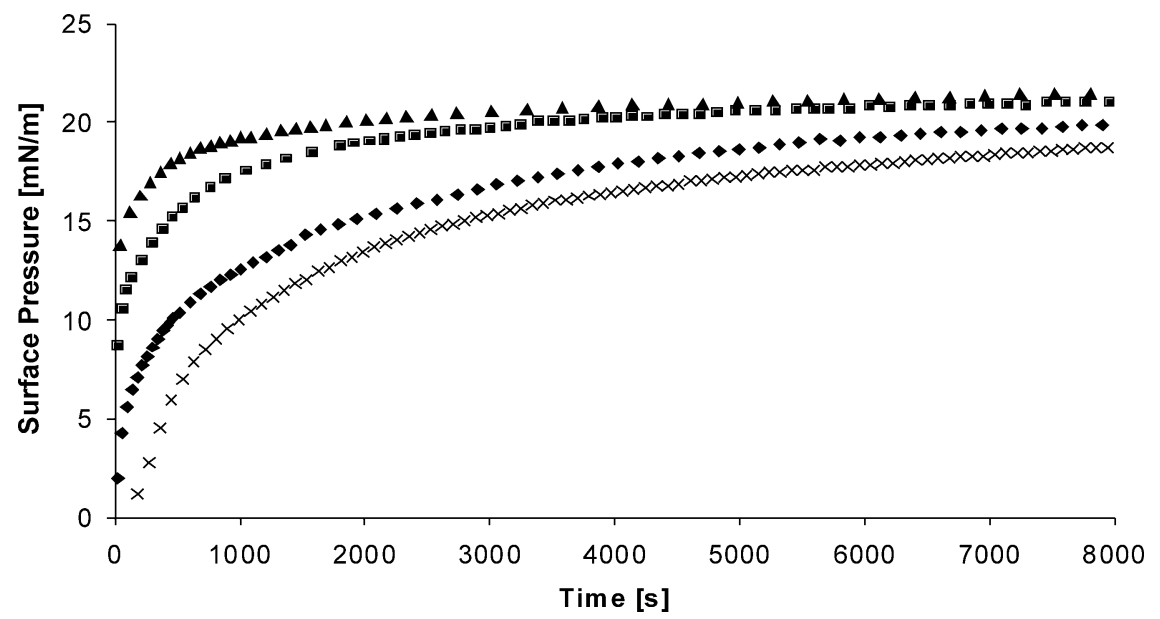

(A)

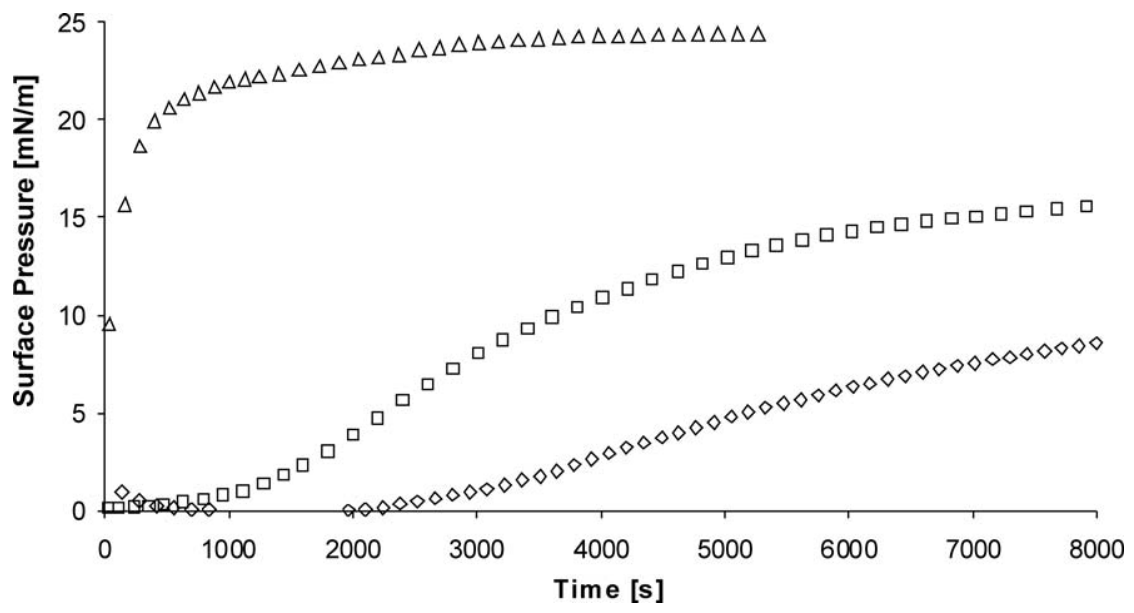

(B)

Fig. 1. Surface pressure as a function of time for $\beta$-lactoglobulin (A, $0.5(\mathbf{\Lambda}), 0.1$ $0.05(\diamond) \mathrm{mg} / \mathrm{mL})$.

$1.3327, \mathrm{~d} n / \mathrm{d} c=0.18$ [47]; the angle of incidence was $50^{\circ}$. Using the combination of ellipsometry and surface tensiometry, both the increase of surface load $(\Gamma)$ and surface pressure $(\Pi)$ in time could be determined. The rate of adsorption from protein solutions $0.005-0.5 \mathrm{mg} / \mathrm{mL}$ (10 mM phosphate, $\mathrm{pH} 7.0$, $20^{\circ} \mathrm{C}$ ) was measured in duplicate. All experiments were started by removing the interfacial layer with a custom made suction device after which the clean interface was rapidly expanded to the maximum area (from 30 to $190 \mathrm{~cm}^{2}$ ). The first datapoints taken are typically $100 \mathrm{~s}$ after cleaning the interface. In this way, the initial conditions for each experiment approximated $\Gamma=0 \mathrm{mg} / \mathrm{m}^{2}$ at $t=0 \mathrm{~s}$. Control experiments with destilled water in between measurements confirmed that the cleaning method used (rinsing with ethanol and water) was sufficient to avoid contamination of the trough.

\section{Results and discussion}

\subsection{Adsorption behavior}

To link the potential unfolding of proteins at the interface to the exerted surface pressure, the kinetics of surface pressure development was monitored as a function of the protein bulkconcentration for $\beta$-lactoglobulin $(\beta$-lg) and ovalbumin, which have different folding stabilities in the bulk. The adsorption of these proteins was studied for three bulk concentrations: 0.5 , 0.1 and $0.05 \mathrm{mg} / \mathrm{mL}$ (for $\beta$ - $\lg$ also $0.005 \mathrm{mg} / \mathrm{mL}$ is included). In Fig. 1 the surface pressure is plotted against the adsorption time. For $\beta$-lg a decrease in both the rate of surface pressure development and plateau value of the surface pressure $\left(\Pi_{2 \mathrm{~h}}\right)$ are observed with decreasing concentration $\left(\Pi_{2 \mathrm{~h}}\right.$ decreases from 25 to $16 \mathrm{mN} / \mathrm{m}$ ). However, from the figure it can be seen that at all concentrations the interfacial surface pressure reaches a plateau-value within the time-span of the experiment. For ovalbumin saturation is reached at the highest, but not at lower concentrations (Fig. 1B, $\Pi_{2 \mathrm{~h}}$ decreases from 23 to $7 \mathrm{mN} / \mathrm{m}$ ). Furthermore, a lag-time is found for the lower concentrations; at $0.05 \mathrm{mg} / \mathrm{mL}$ it takes $2000 \mathrm{~s}$ before surface pressure starts to increase.

To test whether the difference between the development of surface pressure by $\beta$-lg and ovalbumin is due to a change in the adsorption kinetics, the adsorbed amount $(\Gamma)$ in time for the same experiments was monitored by ellipsometry and plotted in Fig. 2. Here also a decrease in the rate of adsorption is ob- 


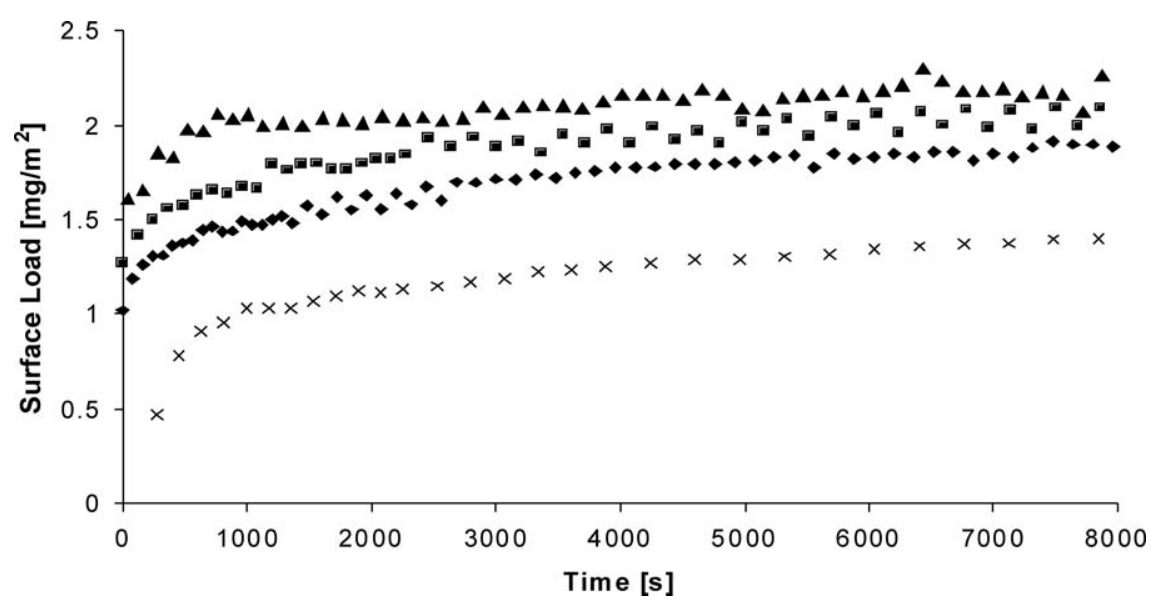

(A)

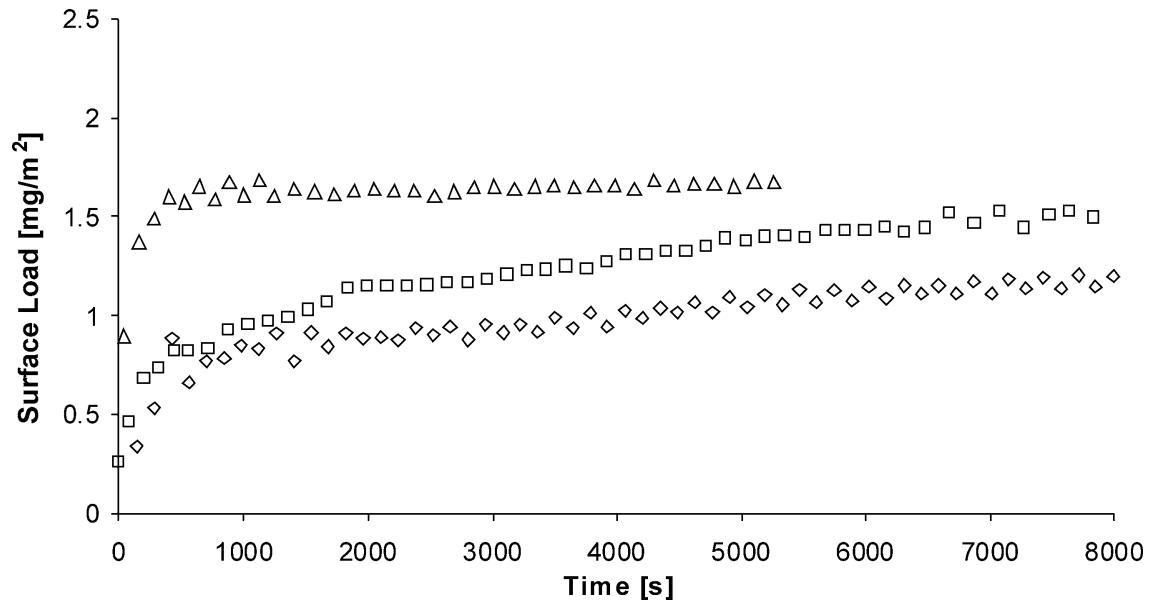

(B)

Fig. 2. Surface load as a function of time for $\beta$-lactoglobulin (A, $0.5(\mathbf{\Lambda}), 0.1$

and 0.05 , and $0.005(\times) \mathrm{mg} / \mathrm{mL})$ and ovalbumin $(\mathrm{B}, 0.5(\triangle), 0.1(\square)$ and $0.05(\diamond) \mathrm{mg} / \mathrm{mL})$.

served for both proteins at lower concentrations, but the largest difference between the two proteins is found in the plateauvalue of adsorption. The maximal adsorbed amount of $\beta-\lg$ decreases from $2 \mathrm{mg} / \mathrm{m}^{2}$ at 0.5 and $0.1 \mathrm{mg} / \mathrm{mL}$ to $1.2 \mathrm{mg} / \mathrm{m}^{2}$ at $0.005 \mathrm{mg} / \mathrm{mL}$. This latter value is close to that of ovalbumin at the lowest concentration, while at the highest concentration the adsorbed amount of ovalbumin $\left(1.6 \mathrm{mg} / \mathrm{m}^{2}\right)$ is lower than of $\beta-\lg$.

A better view on the effect of concentration on the adsorption behavior is obtained by plotting the surface pressure against the adsorbed amount, now also including results obtained from experiments at intermediate concentrations (Fig. 3). For $\beta$-lg, a decrease in bulk concentration of the protein results in a shift in the $\Pi-\Gamma$ curve to lower values of $\Gamma$ (Fig. 3A). The surface pressure is related to the interaction energy between adsorbed proteins. Apparently the interaction energy between $\beta$-lg adsorbed from low bulk concentrations is higher at certain $\Gamma$ than when the proteins are adsorbed from higher bulk concentrations. In contrast, no shift in the $\Pi-\Gamma$ curve of ovalbumin is observed (Fig. 3B). The only effect of bulk concentration is that the adsorbed amount at the saturation is lower (as seen in Fig. 2B), and subsequently also the maximal surface pressure reached is lower. This is due to the fact that the mea- surement time was restricted to 8000 s. Since the adsorption rate is also determined by the bulk concentration, a decrease in the concentration of a factor 10 would also mean an approximate increase in the time to reach adsorption of a factor 100, according to the Ward and Tordai equation.

In contrast to $\beta$-lg the interactions between adsorbed ovalbumin molecules are not affected by the bulk concentration. Since the possible contribution of electrostatic and hydrophobic interactions to the surface pressure is expected to be independent of the bulk concentration there must be another explanation for the shift in the $\Pi-\Gamma$ curve with decreasing the bulk concentration, as observed for $\beta$-lg. Unfolding is a likely explanation, since it would result in a change in the apparent size of the adsorbed proteins. This would subsequently lead to increased surface pressure at lower values of $\Gamma$. Moreover, unfolding leads to the exposure of previously buried groups what may further affect the protein interaction potential.

A measure of the tendency of a protein to unfold is the protein structural stability, typically described by the free energy of unfolding ( $\Delta G_{\text {unf }}$ ). To test whether the concentration dependence of $\beta$-lactoglobulin could be the result of a lower structural stability, the intrinsic fluorescence at increasing urea concentrations was measured. The normalized fluorescence in- 


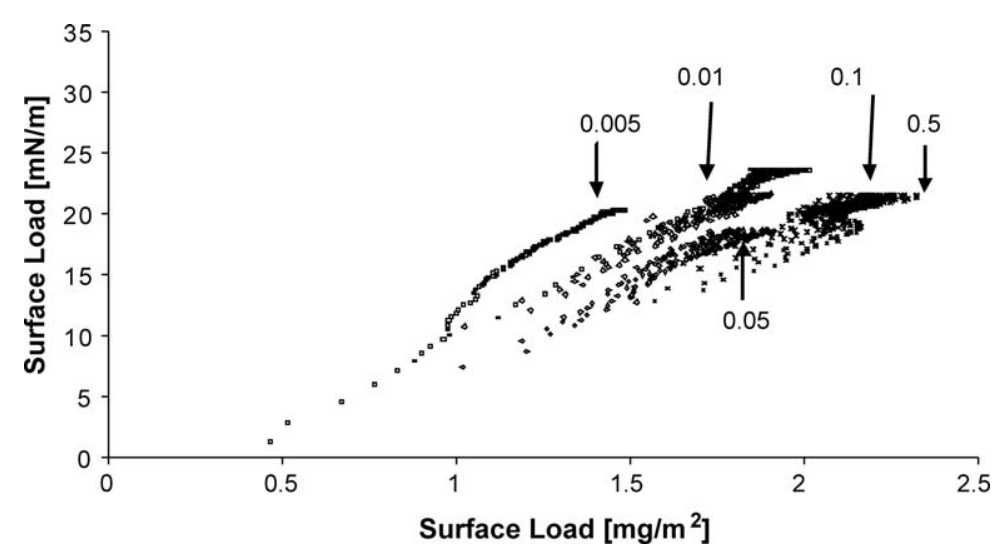

(A)

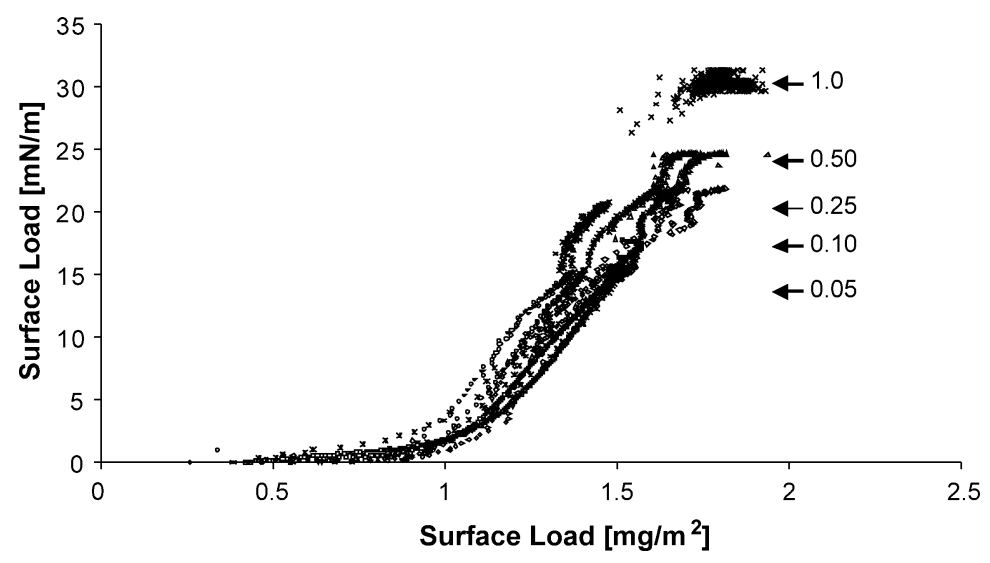

(B)

Fig. 3. Surface pressure vs surface load, for $\beta$-lactoglobulin $(\mathrm{A}, 0.5-0.005 \mathrm{mg} / \mathrm{mL})$ and ovalbumin $(\mathrm{B}, 1.0-0.05 \mathrm{mg} / \mathrm{mL})$, labels with arrows indicate which curve belongs to which concentration.

tensity, which is a measure of the fraction of unfolded protein, is plotted against the urea concentration (Fig. 4). The free energy of unfolding ( $\left.\Delta G_{\text {unf }}\right)$ was calculated from these data assuming a two-state unfolding transition as described elsewhere [44, 45], and the obtained values are given in Table 1. For ovalbumin and $\beta$-lg these values were found to be 33 and $27 \mathrm{~kJ} / \mathrm{mol}$, respectively. To evaluate whether the difference in structural stability is the explanation for the shift in the $\Pi-\Gamma$ curve at different bulk concentrations, a comparison should be made with proteins that only differ in structural stability. Modification of cytochrome $c$ can be used to obtain a protein with identical primary sequence and structural fold, but with decreased stability of the globular structure [43]. This destabilized variant was produced by inhibiting the ligation of methionine- 80 to the heme group as described in the method section. The titration curves for cytochrome $c$ and the destabilised form are also given in Fig. $4,{ }^{1}$ and the derived values for $\Delta G_{\text {unf }}$ in Table 1 . Cytochrome $c$ is more stable than ovalbumin $(40 \mathrm{~kJ} / \mathrm{mol})$, while the destabilised form showed a significantly decreased stability (30 kJ/mol), intermediate to that of $\beta$-lactoglobulin and ovalbumin.

\footnotetext{
1 The absolute fluorescence intensity of cytochrome $c$ increases with increasing urea concentration, therefore we chose to show this data as 1 minus the normalized intensity.
}

Table 1

Molecular parameters for the proteins used in this study

\begin{tabular}{llll}
\hline & $\begin{array}{l}\mathrm{Mw} \\
(\mathrm{kDa})\end{array}$ & $\begin{array}{l}\Delta G_{\text {unf }}{ }^{\mathrm{a}} \\
(\mathrm{kJ} / \mathrm{mol})\end{array}$ & $\begin{array}{l}\Delta E_{\text {act, unf }} \\
(\mathrm{kJ} / \mathrm{mol})\end{array}$ \\
\hline Ovalbumin & 44 & 33 & $340^{\mathrm{b}}$ \\
$\beta-\lg$ & 18 & 27 & $400^{\mathrm{c}}$ \\
Cytochrome $c$ & 12 & 40 & $136^{\mathrm{d}}$ \\
Met-80 mod. Cyt- $c$ & 12 & 30 & n.d.
\end{tabular}

a Calculated from data in Fig. 4.

b From Weijers and Broersen [48].

c From Broersen [44].

d From Mehta et al. [49].

The $\Pi-\Gamma$ curves for both cytochrome $c$ and the destabilized form (at 0.1 and $0.005 \mathrm{mg} / \mathrm{mL}$ ) are given in Fig. 5. Surprisingly, all data are on the same curve. This means that for both cytochrome $c$ and the destabilized variant no effect of bulk concentration is observed. While it was expected that the destabilized form of cytochrome $c$ would show an enhanced ability to unfold at interfaces, this was not reflected in the concentration dependence of the $\Pi-\Gamma$ curve.

From the above, it must be concluded that the $\Delta G_{\mathrm{unf}}$ is not the key parameter that describes the tendency of a protein to unfold at the air-water interface. To understand this better, we must first consider what the driving force for interfacial unfolding would be. In Fig. 6 a schematic representation is given 


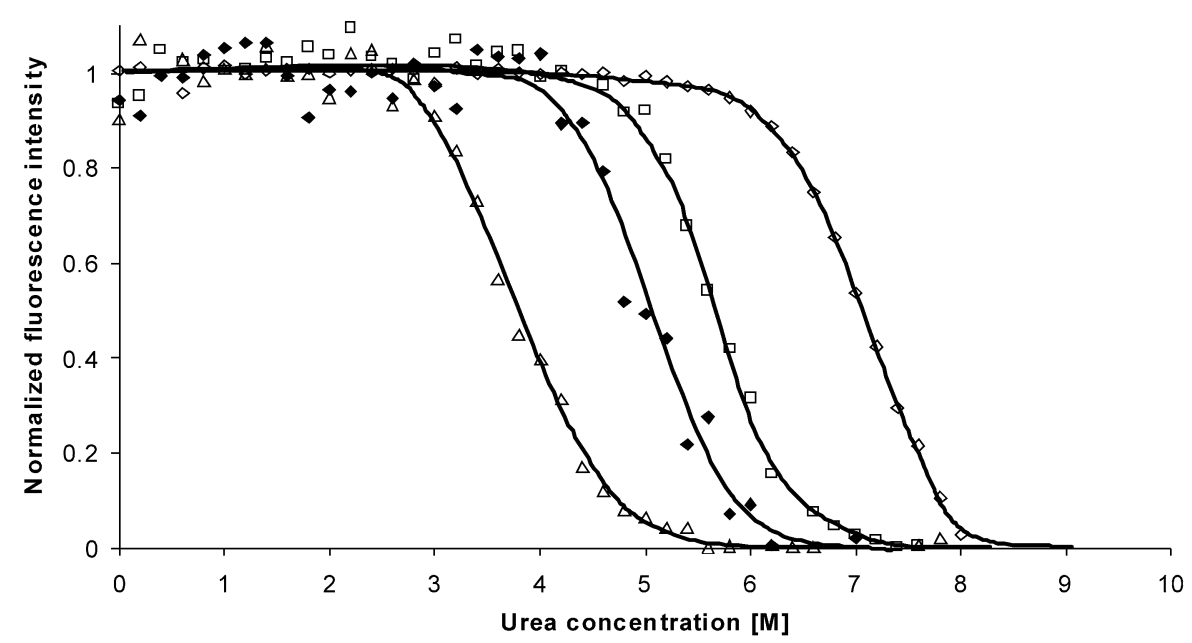

Fig. 4. Normalized fluorescence intensity as a function of the urea concentration for $\beta$-lactoglobulin $(\triangle)$, ovalbumin ( $\square$ ), cytochrome $c(\diamond)$ and Met-80 cytochrome $c$

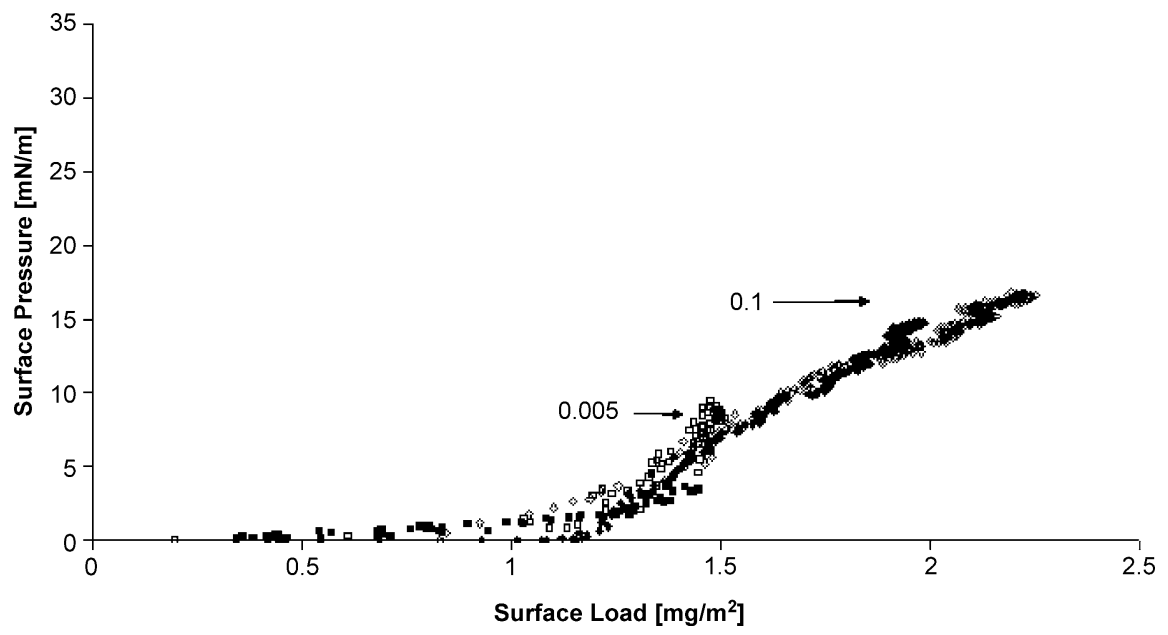

Fig. 5. Surface pressure vs surface load, for cytochrome $c(\square, \diamond)$ and Met-80 cytochrome $c(\mathbf{\square}, \diamond)$ at $0.005(\square)$ and $0.1 \mathrm{mg} / \mathrm{mL}(\diamond)$.

of a protein at the interface. In this figure the arrows indicate the forces acting on the protein. The surface tension between air-water will act as a force towards expansion of the protein, while the surface tension between the protein and both bulk phases will result in a force towards retention of the globular shape [50]. This situation is an analogy to the spreading of oil-droplets at the air-water interface. In this case, a simple calculation of the spreading coefficient [51] will tell whether the oil droplet spreads or if it keeps its globular form.

In the aqueous phase (bulk) the structure of globular proteins is defined, and the population of the unfolded state is very small for most globular proteins. To reach a (partially) unfolded state an activation energy needs to be overcome that is related to the breaking of for example ion-pairs on the protein surface and disruption of H-bonds and van der Waals interaction between side-chain residues. In the case of $\beta$-lactoglobulin and ovalbumin the structure is further stabilised by covalent disulphide bridges. In aqueous solution a significant population of a more unfolded state can only be achieved by the presence of a denaturant or by varying a system parameter, like temperature; in both cases the Gibbs energy of the folded state increases,

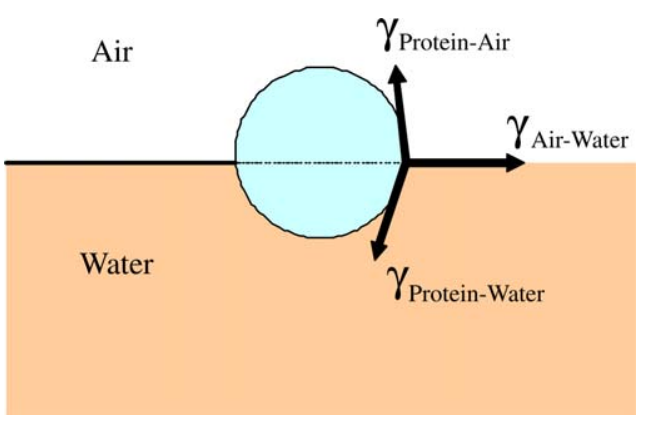

Fig. 6. Schematic representation of the forces acting on a protein at the airwater interface.

resulting in an increasing fraction of unfolded proteins. Similarly the spreading of proteins at the interface is constrained by the structural stability, leading to an (activation) energy barrier of unfolding. This barrier determines how fast proteins can unfold when the spreading coefficient is $>0$. While $\Delta G_{\text {unf }}$ reflects the change in free energy as a result of unfolding, this parameter is not directly related to the activation energy required to go from the folded to the unfolded state. The experiments illustrate 


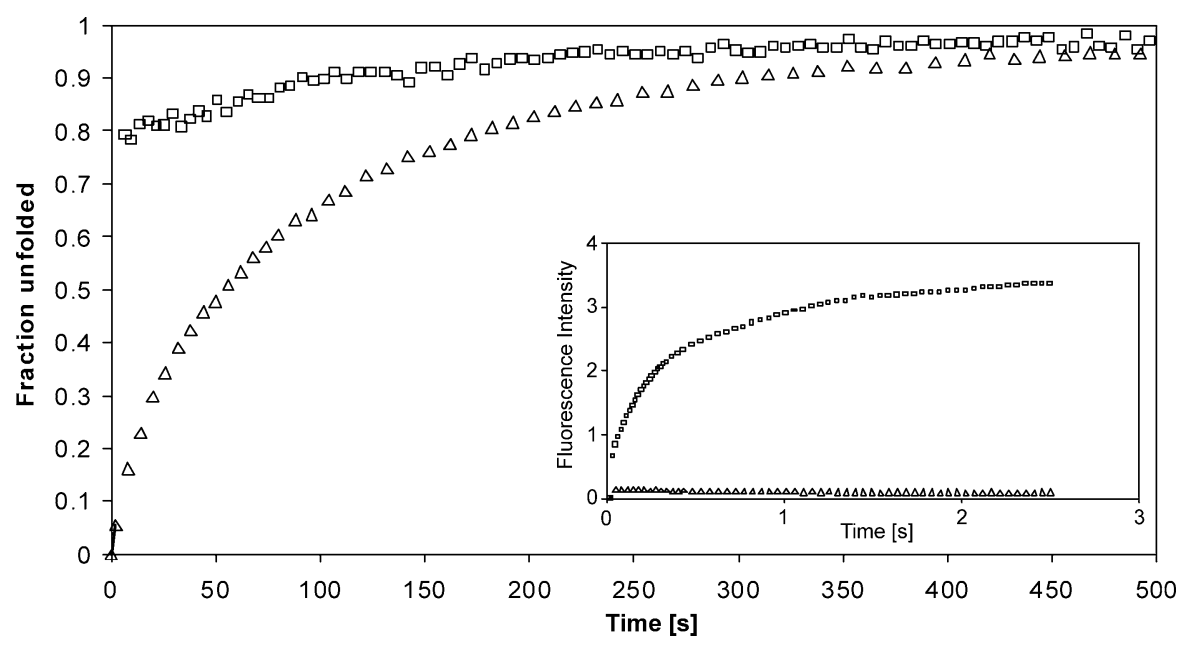

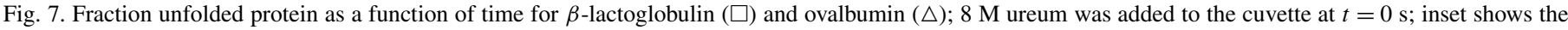
unfolding of the same samples at short times as measured by stopped-flow fluorescence (data from Ref. [44]).

that the interfacial unfolding is limited by the time available for such unfolding processes. Both the effect of adsorption kinetics on the shift of the $\Pi-\Gamma$ curve and the fact that the shift in these curves exists over long periods of time suggest that the adsorbed state does not necessarily reach thermodynamic equilibrium. Rather, the unfolding of the adsorbed proteins seems to be governed by kinetic processes.

A good way to evaluate the energy barrier to unfolding can be obtained by monitoring the kinetics of unfolding. Therefore, the intrinsic fluorescence of ovalbumin and $\beta$-lg was monitored as a function of time, after addition of $8 \mathrm{M}$ urea. The results are shown in Fig. 7. As can be seen in this figure, the unfolding of ovalbumin under the given conditions is only completed after $500 \mathrm{~s}$, whereas for $\beta$-lactoglobulin the unfolding proceeds too fast to be accurately determined with this technique. To illustrate this, results from a stopped flow experiment performed by Broersen et al. [44], using the method as described by Kuwajima et al. [52] under similar conditions are shown in the inset in Fig. 7. From the inset it becomes clear that $\beta$-lg unfolds almost completely at a time-scale of (sub-)seconds; while cytochrome $c$ shows even faster (milliseconds) unfolding than $\beta$-lactoglobulin (results not shown). By measuring the kinetics of unfolding at different concentrations of urea and at different temperatures, the activation energy for unfolding ( $\Delta E_{\text {act, unf }}$ ) can be established; the values reported in literature are given in Table 1. Activation energies are in the order of $100-400 \mathrm{~kJ} / \mathrm{mol}$, while the difference in free energy between the folded and unfolded state is only in the order of $10-50 \mathrm{~kJ} / \mathrm{mol}$. In view of these activation energies it can be expected according to the Arrhenius equation that when unfolding of $\beta$-lactoglobulin occurs at a time-scale of seconds, this will be at the $10-100 \mathrm{~s}$ time-scale for ovalbumin (as indeed illustrated in Fig. 7) and at the microsecond time-scale for cytochrome $c$. Destabilisation of cytochrome $c$ will only cause this process to speed up (no

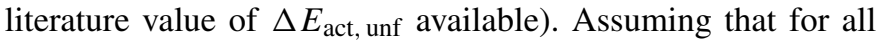
proteins the spreading coefficient is not the limiting factor, the time that the spreading force can act unperturbed on the protein will determine whether the protein will unfold. As can be seen from Fig. 2, the situation where no protein-protein interactions develop (i.e. where $\Pi<1 \mathrm{mN} / \mathrm{m}$ ) is typically in the order of seconds for $\beta$-lg and cytochrome $c$. Obviously this time frame will allow most of the cytochrome $c$ (modified or not) to unfold at the interface. The unfolding kinetics of ovalbumin is simply too slow and even though at very low bulk concentrations the surface pressure does not increase until after $2000 \mathrm{~s}$, no unfolding takes place. Apparently only for $\beta$-lactoglobulin both the unfolding kinetics and $\Delta E_{\text {act, unf }}$ are exactly in the critical range, where the folding state of the adsorbed protein depends on the rate of adsorption and thus on the bulk concentration.

\section{Conclusion}

The present work focused on the question whether the state of folding of adsorbed protein is affected by the bulk concentration. From the presented results, it is concluded that a change in the protein folded state can take place. However, this change does not depend on the stability of the protein as given by the change in free energy between the folded and the unfolded states. Rather, the process appears to be determined by the activation energy of unfolding, the spreading coefficient and the time available for unfolding. The unfolding was demonstrated by a shift in the $\Pi-\Gamma$ curve measured for $\beta$-lactoglobulin adsorbed from different bulk concentrations. For ovalbumin no evidence of additional unfolding was found, which is attributed to the fact that the unfolding of this protein is too slow. On the other hand, for cytochrome $c$ also no changes in the $\Pi-\Gamma$ curve were found, but based on the very rapid unfolding of this protein it is suggested that in this case the proteins all reach the same unfolded state at the interface.

The fact that the state of folding of adsorbed proteins can depend on the history of the adsorbed layer poses a serious challenge for the theoretical description of the adsorbed layer. However, only if the adsorption rate is close to the rate of unfolding, changes in bulk concentrations can lead to different adsorbed states. For practical applications, a rapid adsorption of proteins is necessary for foam formation. If the protein concentration is too low, or if the adsorption process is too slow, 
no foam is formed. This means that in such systems only proteins that have unfolding kinetics on the millisecond to second time-scale will be sensitive for changes in adsorption kinetics.

Finally, the fact that the unfolding of adsorbed proteins can lead to a shift in the $\Pi-\Gamma$ curve, strongly suggests that this folding state is not purely determined by the surface pressure at the interface. It would even seem that once a protein has reached a certain state of unfolding at the interface, this (new) conformational state is retained even when the adsorption process continues. From these results it must be concluded that the role of unfolding in the description of adsorbed layers that has been the consensus in literature should be reconsidered.

Unfolding is neither necessary, nor a driving force for protein adsorption. Only after adsorption the protein can adopt to its new environment. This transition needs to occur at a timescale that is shorter than the adsorption rate of neighboring proteins. From this it follows that the increase of surface pressure after saturation of the interface (constant $\Gamma$ ) cannot be attributed by unfolding processes.

\section{References}

[1] S.H. Chang, L.Y. Chen, W.Y. Chen, Colloids Surf. B: Biointerfaces 41 (2005) $1-6$.

[2] J.R. Clarkson, Z.F. Cui, R.C. Darton, J. Colloid Interface Sci. 215 (1999) 323-332.

[3] D.E. Graham, M.C. Phillips, J. Colloid Interface Sci. 70 (1979) 403-414.

[4] L.K. James, Lg. Augenste, Adv. Enzymol. Relat. Areas Mol. Biol. 28 (1966) $1-40$.

[5] T.L. Donaldson, E.F. Boonstra, J.M. Hammond, J. Colloid Interface Sci. 74 (1980) 441-450.

[6] D.E. Graham, M.C. Phillips, J. Colloid Interface Sci. 70 (1979) 427-439.

[7] C.J. Beverung, C.J. Radke, H.W. Blanch, Biophys. Chem. 81 (1999) 5980.

[8] A. Ball, R.A.L. Jones, Langmuir 11 (1995) 3542-3548.

[9] J.E. Kinsella, Food Chem. 7 (1981) 273-288.

[10] C.S. Rao, S. Damodaran, Langmuir 16 (2000) 9468-9477.

[11] S. Damodaran, J. Food Sci. 70 (2005) R54-R66.

[12] J.S. Erickson, S. Sundaram, K.J. Stebe, Langmuir 16 (2000) 5072-5078.

[13] V.B. Fainerman, R. Miller, Langmuir 15 (1999) 1812-1816.

[14] V.B. Fainerman, E.H. Lucassen-Reynders, R. Miller, Adv. Colloid Interface Sci. 106 (2003) 237-259.

[15] I. Dekany, J. Nemeth, M. Szekeres, R. Schoonheydt, Colloid Polym. Sci. 282 (2003) 1-6.

[16] Z. Horvolgyi, M. Mate, A. Daniel, J. Szalma, Colloids Surf. A: Physicochem. Eng. Aspects 156 (1999) 501-507.

[17] E. Wolert, S.M. Setz, R.S. Underhill, R.S. Duran, M. Schappacher, A. Deffieux, M. Holderle, R. Mulhaupt, Langmuir 17 (2001) 5671-5677.

[18] H. Du, Y.B. Bai, Z. Hui, L.S. Li, Y.M. Chen, X.Y. Tang, T.J. Li, Langmuir 13 (1997) 2538-2540.

[19] H. Schwartz, Y. Harel, S. Efrima, Langmuir 17 (2001) 3884-3892.

[20] E. Dickinson, Y. Matsumura, Colloids Surf. B: Biointerfaces 3 (1994) 117.

[21] P.J. Atkinson, E. Dickinson, D.S. Horne, F.A.M. Leermakers, R.M. Richardson, Ber. Bunsen-Ges. Phys. Chem. Chem. Phys. 100 (1996) 994 998.
[22] P.J. Atkinson, E. Dickinson, D.S. Horne, R.M. Richardson, J. Chem. Soc., Faraday Trans. 91 (1995) 2847-2854.

[23] B. Berge, P.F. Lenne, A. Renault, Curr. Opin. Colloid Interface Sci. 3 (1998) 321-326.

[24] E. Dickinson, D.S. Horne, J.S. Phipps, R.M. Richardson, Langmuir 9 (1993) 242-248.

[25] E. Dickinson, D.S. Horne, R.M. Richardson, Food Hydrocolloids 7 (1993) 497-505.

[26] B. Harzallah, V. Aguie-Beghin, R. Douillard, L. Bosio, Int. J. Biol. Macromol. 23 (1998) 73-84.

[27] D.S. Horne, P.J. Atkinson, E. Dickinson, V.J. Pinfield, R.M. Richardson, Int. Dairy J. 8 (1998) 73-77.

[28] J.R. Lu, T.J. Su, R.K. Thomas, J. Colloid Interface Sci. 213 (1999) 426437.

[29] J.R. Lu, R.K. Thomas, J. Chem. Soc., Faraday Trans. 94 (1998) 995-1018.

[30] M.B.J. Meinders, G.G.M. van den Bosch, H.H.J. de Jongh, Eur. Biophys. J. 30 (2000) 256-267.

[31] M.B.J. Meinders, G.G.M. van den Bosch, H.H.J. de Jongh, Trends Food Sci. Techn. 11 (2000) 218-225.

[32] M.B.J. Meinders, H.H.J. De Jongh, Biopolymers 67 (2002) 319-322.

[33] H.H.J. de Jongh, M.B.J. Meinders, Spectrochim. Acta, Part A: Mol. Biomol. Spectrosc. 58 (2002) 3197-3204.

[34] E.V. Kudryashova, M.B.J. Meinders, A. Visser, A. van Hoek, H.H.J. de Jongh, Eur. Biophys. J. Biophys. Lett. 32 (2003) 553-562.

[35] E.V. Kudryashova, A. Visser, H.H. De Jongh, Protein Sci. 14 (2005) $483-$ 493.

[36] J.R. Lu, T.J. Su, B.J. Howlin, J. Phys. Chem. B 103 (1999) 5903-5909.

[37] J.R. Lu, T.J. Su, R.K. Thomas, J. Penfold, J. Webster, J. Chem. Soc., Faraday Trans. 94 (1998) 3279-3287.

[38] S.J. McClellan, E.I. Franses, Colloids Surf. B: Biointerfaces 28 (2003) 63-75.

[39] L. Jorgensen, M. Van De Weert, C. Vermehren, S. Bjerregaard, S. Frokjaer, J. Pharm. Sci. 93 (2004) 1847-1859.

[40] F.A. Husband, M.J. Garrood, A.R. Mackie, G.R. Burnett, P.J. Wilde, J. Agric. Food Chem. 49 (2001) 859-866.

[41] H.H.J. de Jongh, T. Groneveld, J. de Groot, J. Dairy Sci. 84 (2001) $562-$ 571.

[42] H.A. Kosters, K. Broersen, J. de Groot, J. Simons, P. Wierenga, H.H.J. de Jongh, Biotechnol. Bioeng. 84 (2003) 61-70.

[43] H.H.J. de Jongh, E. Goormaghtigh, J.M. Ruysschaert, Biochemistry 34 (1995) 172-179.

[44] K. Broersen, M.B.J. Meinders, R.J. Hamer, A.G.J. Voragen, H.H.J. de Jongh, submitted for publication.

[45] A. Matouschek, J.T. Kellis, L. Serrano, M. Bycroft, A.R. Fersht, Nature 346 (1990) 440-445.

[46] S.C. Russev, T.V. Arguirov, T.D. Gurkov, Colloids Surf. B: Biointerfaces 19 (2000) 89-100.

[47] E.G. Longsworth, J. Am. Chem. Soc. 70 (1948) 2719-2724.

[48] K. Broersen, M. Weijers, J. de Groot, R.J. Hamer, H.H.J. de Jongh, in preparation.

[49] R. Mehta, A. Kundu, N. Kishore, Phys. Chem. Chem. Phys. 5 (2003) 5514-5522.

[50] M.A. Cohen Stuart, W. Norde, J.M. Kleijn, G.A. van Aken, in: E. Dickinson (Ed.), Thermodynamic and Adsorption Kinetic Studies of Protein + Surfactant Mixtures, Royal Soc. Chem., Cambridge, 2005, pp. 99-119.

[51] N.E. Hotrum, T. van Vliet, M.A.C. Stuart, G.A. van Aken, J. Colloid Interface Sci. 247 (2002) 125-131.

[52] K. Kuwajima, M. Mitani, S. Sugai, J. Mol. Biol. 206 (1989) 547-561. 